\title{
Integration of Point and Remote Sensing Data for Monitoring Surface Runoff around Madinah City, Saudi Arabia
}

\author{
El Sayed Hermas',2, Mohammed El-Barodi'2, Khalid Al-Ghamdi² \\ ${ }^{1}$ The National Authority of Remote Sensing and Space Sciences, Cairo, Egypt \\ ${ }^{2}$ Geography Department, Faculty of Social Sciences, Umm Al-Qura University, Makkah, Saudi Arabia \\ Email: eaibrahim@uqu.edu.sa
}

Received 23 October 2015; accepted 11 December 2015; published 14 December 2015

Copyright (C) 2015 by authors and Scientific Research Publishing Inc.

This work is licensed under the Creative Commons Attribution International License (CC BY).

http://creativecommons.org/licenses/by/4.0/

(c) (i) Open Access

\section{Abstract}

In response to sporadic rainy storms, the fluvial catchments in the northern, eastern and southern regimes of Medina City produce surface runoff that varies in the frequency and magnitude. The determination of the most frequently flowing catchment(s) through each precipitation event and the spatial characteristics of surface runoff still represent gaps in understanding the hydrological processes associated with flash floods in arid environments. The lack of data in particular precipitation records at reliable temporal and spatial scales is considered one of the essential constraints in understanding these issues. The integration of point precipitation records and the multi-temporal satellite imagery such as LandSat TM and the Tropical Rainfall Monitoring Mission (TRMM) helped retrieve significant surface runoff events through two decades of the last century around Madinah City. The spectral signatures of surface runoff have been clearly identified from the optical remote sensing images acquired after each precipitation event. Investigating the spectral signatures of surface runoff along with its corresponding precipitation records from both Madinah climatic station and the TRMM monthly precipitation indicated that 1) there is no specific threshold of the amount of precipitation required for developing surface runoff; 2) while Madinah climatic station provided records of precipitation on the majority of surface runoff, it did not provide records on some monitored surface runoff events; 3) the spatial distribution and magnitude of the monthly precipitation of the TRMM images of 1998 have been conformed with all surface runoff events developed in W. Al-Aqeeq; and 4) W. Al-Aqeeq is considered the most frequently flowing valley around Madinah City because it developed surface runoff in response to all the precipitation events. These results emphasize the necessity of establishing a number of climatic and gauge stations in selective locations within the drainage basins around Madinah City. This proposition can facilitate studying the various rainfall and runoff characteristics for designing proper surface water harvesting strategy. 
Keywords

Surface Runoff, Remote Sensing, TRMM, Madinach City, DEM

\section{Introduction (Heading 1)}

The majority of Saudi landscape is mountainous areas sculptured by well-developed drainage basins of various sizes and outlets. As an arid region, short and intensive rainy storms produce surface runoff. Under the prevalence of steep slopes, high topography, and scarce vegetation cover, the valley of these hydrographic basins produces hazardous flash floods that vary in their frequency and magnitudes (Figure 1).

Traditionally, the potential of these hydrographic basins to produce flash floods and the associated hazards against land use has been assessed based upon the analysis of their morphometric parameters [1]-[6]. Although these kinds of studies are valuable for the characterization of the flash flood potential, they are considered qualitative approaches for studying and assessing the hydrologic characteristics of a given hydrographic basin. In some cases, some field measurements are conducted to determine the quantity of surface runoff through selected locations across the major valleys of the hydrographic basins. Field measurements such as the depth of surface runoff and valley width at selected locations are normally carried out either during or immediately after the occurrence of a flash flood event. These measurements include the determination of the depth of surface runoff, velocity of surface runoff, and cross sectional area of the valley enabled quantification of surface runoff at selected locations along the major valleys of given drainage basins. Very limited studies were carried out using this approach, anyway, in the Kingdom of Saudi Arabia [7] [8]. Although field measurements allow the quantification of surface runoff, they are localized and can not express the total volume of surface runoff in the entire drainage basin. In addition, little is known about which basin(s) do frequently flow in each rainy storm and which do not. The spatial characteristics of flash floods such as the spatial extents are unknown as well. Recently, systematic and constant availability of remotely sensed data can help hydrologist determine the most frequently flowing drainage basins and the spatial extents of surface runoff of a given flash flood event.

With the advantages of the availability of the precipitation data from the Tropical Rainfall Mapping Mission (TRMM), and the multi-temporal satellite imagery of the LandSat sensors (TM and ETM), along with the available Shuttle Radar Topographic Mission (SRTM) Digital Elevation Model (DEM), understanding many aspects of the hydrological processes associated with flash floods has been enhanced [9]-[18]. These studies helped define the spatial extents of the surface runoff of a flash flood event, and uniquely determine whether the associated mass of water and sediment is transmitted at the most downstream outlet or fully transmitted through the alluvial deposits to the shallow terrestrial aquifers. However, the integration between the previous data is considered limited for appropriate mapping, modeling, and forecasting the hydrological processes of a given area. For instance, the absence of calibrated TRMM and the in-situ gauged measurements of flow characteristics suppress the construction of accurate peak-hydrographs of flash floods. In addition, the temporal and spatial variations of important hydrological parameters such as evapo-transpiration, precipitation, and soil moisture content are not represented as well. In this research activity, the various hydrological parameters extracted from

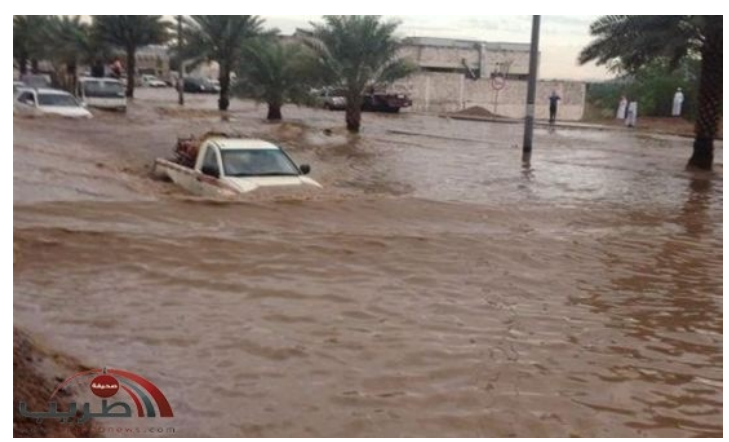

Figure 1. An example of flash flood hazards against road network located in W. Qanah, north Madinah City. 
the SRTM DEM will be integrated with time series TM and ETM lands at satellite imagery to determine the most frequent flowing watershed in the upstream reaches that converge in the westward direction north Madina city, KSA. In addition, the spatial characteristics of one of the most intensive rainy storms over these basins will be presented and analyzed using TRMM data in particular through successive surface runoffs occurred in 1998.

\section{Study Area}

The study area includes the regions occupied by the drainage basins in the east, south, and north of Madinah City, KSA. Geographically, it is located between $39^{\circ} 14^{\prime} 35^{\prime \prime}$ to $42^{\circ} 17^{\prime} 2 " \mathrm{E}$, and $23^{\circ} 12^{\prime} 16^{\prime \prime}$ to $25^{\circ} 37^{\prime} 29^{\prime \prime} \mathrm{N}$. Madinah City is located in the center of the western limit of the study area (Figure 2). The spatial extent of the study area is approximately $43,750 \mathrm{~km}^{2}$. The entire study area represents the upstream ranges of a large drainage basin that has its most downstream outlet at the coast of the Red Sea south Wejh city. The monthly averages of temperature of Madinah surroundings range from a minimum of $19.3^{\circ} \mathrm{C}$ to a maximum of $37.5^{\circ} \mathrm{C}$. The monthly averages of precipitation values range from 0.0 to $37.4 \mathrm{~mm}$. Summer is hot with minimal chances of rainfall whereas winter is cold with high chances of rainfall through autumn and winter. Geologically, as a part of the Arabo-Nubian shield, the area has long history of tectonics and geologic events that produces complex lithologic and structural settings. Basement rocks include Halpan group, Mardamah group, and plutonic igneous rocks. These rocks vary in their compositions from metamorphic rocks to acidic igneous rocks [19], and occupy the majority of the study areas in particular in the east, southeast, and southwest. One of the main lithologic components in the study area is the volcanic rocks that have been erupted since the formation of Red Sea, and still active [20]. In the west of the study area, the volcanic rocks form a wide strip extending from the southern limit northward till the eastern boundaries of Madinah City (Figure 2). In addition, they are well represented in the northern reaches of the study area as well. Volcanic rocks plays potential role in developing surface runoff through the alluvial valleys of the study area. Locally, these rocks are recognized as Harrat Al-Safah and Harrat Al-Hazm in the north of Madinah City, Harrat Al-Qaffef and Harrat Al-Harma in the east of Madinah City, and

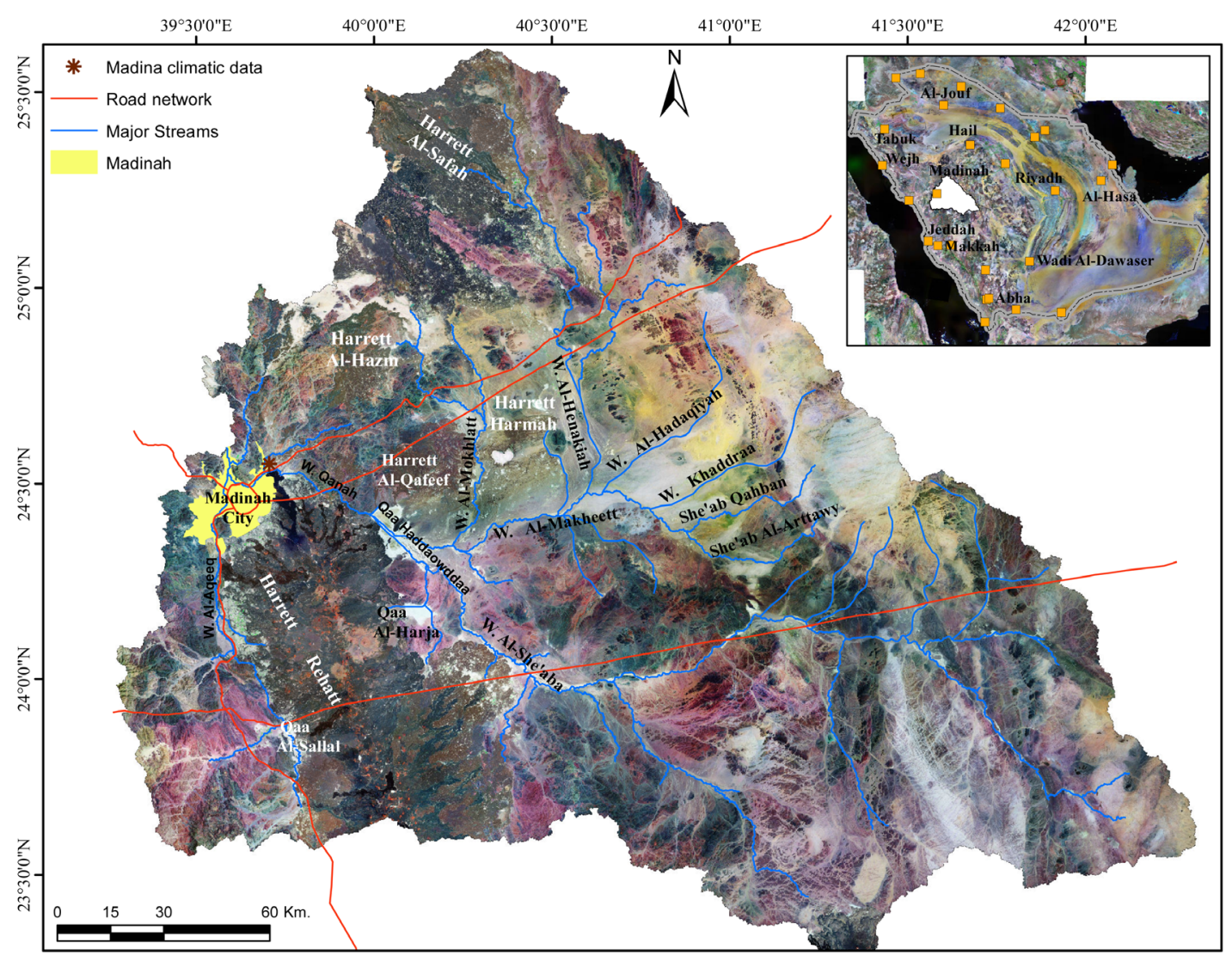

Figure 2. The location of the study area. 
Harrat Rehatt that represents an elongated wide strip south Madinah City (Figure 2). Beside the volcanic rocks, many surface sinks at variable widths are located such as Qaa Haddaowddaa, Qaa Al-Sallal, and Qaa Al-Harja. Many major valleys discharge in these sinks through the occurrence of flash flood events (Figure 2).

Along with the basement and volcanic rocks, the alluvial deposits are well represented within the valleys of the study areas. The thickness of these alluvial deposits may reach $80.0 \mathrm{~m}$ within most of the valleys implying a long history of erosional and depositional processes in the study area [21]. The active tectonics of the Red Sea that resulted in continuous uplift of the basement rocks in the west of Saudi Arabia along with the dominant arid regime resulted in the high and rugged topography of the study area. The elevation of the study area ranges from 575.0 to $2348.0 \mathrm{~m}$ with a mean of $1402.0 \mathrm{~m}$ asl whereas the slope ranged from 0.0 to 66.0 with a mean of 31.3 denoting the dominance of very steep slope landscape [22]. In response to the hard bedrocks and high rugged topography, the landscape of the study area is characterized by matured and integrated surface drainage networks (Figure 2). This is asserted by the development of $8^{\text {th }}$ order trunk valley that starts to the east of Madinah city by $109.0 \mathrm{~km}$ and continues in the westward direction through Madinah City for a distance of $274.0 \mathrm{~km}$ before the major $9^{\text {th }}$ trunk valley discharges into the Red Sea. Within the area of study, the $8^{\text {th }}$ order trunk valley receives the transported water and sediments from all the watersheds in the study area (Figure 2). The $8^{\text {th }}$ order trunk valley in the middle of the study area comprises two segments. The eastern segment is called Wadi Al-Makheett and the western segment is called Wadi Al-'Aqool or WadiQanah. Between both segments and in the northeast of Harrat Rehatt, Qa'a Haddaowddaa basin occurs (Figure 2). W. Al-Makheett receives surface runoff from the east of the study area through She'ab Al-Arttawy, She'ab Qahban, and W. Khaddraa tributaries, and from the northeast and north through W. Al-Hadaqiyah, W. Al-Henakiah, and W. Al-Mokhlatt tributaries (Figure 2). The southeast region of the study area is occupied by the largest $7^{\text {th }}$ order drainage basin in the study area. The trunk valley of this basin is called W. Al-She'aba which receives surface runoff from the southeast drainage basin and join Wadi Al-Makheett through the southern border of Qa'a Haddaowddaa basin. Along with these $7^{\text {th }}$ order basins, smaller basins confluence with Wadi Al-Makheett as well. The contributions of these small drainage basins to surface runoff at Wadi Al-Makheett are limited. In the west of Qa'a Haddaowddaa basin, surface runoff flow across W. Al-Aqool Dam into the second segment of the $8^{\text {th }}$ order trunk valley which is called W. Qanah. In the north of W. Qanah, many small drainage basins are represented and ranges from $4^{\text {th }}$ to $5^{\text {th }}$ order drainage basins. These basins drain a regime that is formed basically from acidic igneous rocks. To the south of Madinah, Wadi Al-Aqeeq drainage basin occur which is considered one of the largest and most flowing valley in the study area. The Trunk valley of $\mathrm{W}$. Al-Aqeeq receives surface runoff from different lithologic regimes: the volcanic rocks in the east and the igneous acidic rocks in the west (Figure 2). The trunk valley of W. Al-Aqeeq flows northward through the western districts of Madinah to join W. Qanah in the northwest of the city.

\section{Methodology}

A selected dataset of LandSat TM satellite imagery and Tropical Rainfall Monitoring Mission (TRMM) have been used for defining the spatial characteristics of surface runoff events through the last three decades. The spatial characteristics of surface runoff events through 1998 were compared with the spatial distribution of the accumulated rainfall recorded from the TRMM images. The recorded amounts of rainfall that are associated with each surface runoff were accessed from the climatic station located north Madinah City. The spatial characteristics of the surface runoff events were compared with the spatial distributions of the accumulated rainfall recorded from the TRMM images. The DEM was used to extract the various hydrological characteristics such as boundaries of hydrological catchments and stream networks.

\subsection{Acquisition of the Multi-Temporal Satellite Imagery}

The LandSat TM and ETM satellite images were requested and then downloaded from the USGS catalogue (www.glovis.usgu.gov). Bands 7, 4, and 2 have been stacked to produce false color composite images which were used for visual interpretation of the signatures of active channels after each surface runoff event. Both the acquisition dates and the spatial resolution of these images are presented in Table 1. Images that have dates of acquisition after the flash flood event are only acquired. The time between the flash flood event and the date of the acquisition is different which extends from few days through a month. Accordingly, the recognition of the spectral signatures of the active channels associated with surface runoff varies from flash flood event to another. To demonstrate this, the dates and amounts of rainfall events that probably produced surface runoff in the study 
Table 1. A list of the acquired LandSat TM images and the precipitation amounts as recorded from Madinah Climatic station.

\begin{tabular}{|c|c|c|c|c|c|}
\hline \multicolumn{3}{|c|}{ Satellite imagery } & \multicolumn{3}{|c|}{ Climatic Data } \\
\hline Year & Date & $\begin{array}{l}\text { Spatial resolution } \\
\text { m }\end{array}$ & Station \# & Date of rainy storms & $\begin{array}{c}\text { Precipitation } \\
\text { mm }\end{array}$ \\
\hline 1984 & November 29 & 30 & 40430 & November 25 & 18.2 \\
\hline \multirow{2}{*}{1987} & March 4 & 30 & 40430 & March 3 & 26.8 \\
\hline & March 27 & 30 & 40430 & & \\
\hline \multirow[t]{5}{*}{1991} & January 17 & 30 & 40430 & January 17 & 6.0 \\
\hline & & & 40430 & January 4 & 6.0 \\
\hline & IVIartio & 50 & 40430 & February & 0.0 \\
\hline & April 10 & 30 & 40430 & March 29 & 13.6 \\
\hline & & & 40430 & April 29 & 25.2 \\
\hline \multirow[t]{5}{*}{1998} & May 28 & 30 & 40430 & April 30 & 18.8 \\
\hline & & & 40430 & May 10 & 10.3 \\
\hline & September 1 & 30 & 40430 & August 28 & 38.5 \\
\hline & & 30 & 40430 & October & 0.0 \\
\hline & December 6 & 30 & 40430 & November & 0.0 \\
\hline
\end{tabular}

area have been presented as well in Table 1. Although, we have collected long historical remote sensing imagery for the study area, we will focus only on the satellite images of 1984, 1987, 1991, and 1998 to analyze the spatial characteristics of surface runoff associated with each flash flood event.

\subsection{Mapping the Accumulated Rainfall that are Potential to Produce Surface Runoff}

The Tropical Rainfall Monitoring Mission (TRMM) satellite has been launched since 1998. This satellite can provide images of the total accumulated rainfall every month over the entire region of Saudi Arabia. Pixels of these images include the values of the accumulated rainfall $(\mathrm{mm})$ over the entire hydrographic basins of the study area. Since the acquisition started in 1998, particular number of images of different rainy storms will be presented. The magnitude and the spatial distribution of the accumulated rainfall will be analyzed against both the spectral signatures of the selected surface runoff events and the recorded precipitation values of Madinah climatic station.

\subsection{Extracting Hydrological Parameters Using SRTM DEM}

The Shuttle Radar Topography Mission (SRTM) DEM was used to automatically extract the hydrological parameters of the study area following the standard technique of Jenson and Dominique [23]. Firstly, all sinks were removed by filling the DEM. Secondly, the flow direction was computed to define the aspect and gradient of flow for each cell in the DEM. Thirdly, this flow direction grid was accumulated to produce cumulative pattern of all cells within the DEM. Finally, the threshold of flow accumulation layer was defined to extract the boundaries of sub-catchments and the surface stream network developed within the entire catchment of Madinah City.

\section{Results and Discussion}

Although the area is characterized by the availability of considerable numbers LandSat TM and ETM satellite images, only images that demonstrated and described the spectral signatures of surface runoff have been selected. These images belong to 1984, 1987, 1991, and 1998 with emphasis on multiple images of 1998 where there are monthly acquisitions of TRMM data that demonstrated the spatial characteristics and magnitudes of 
precipitation.

\subsection{Surface Runoff of 1984}

In November 25, 1984, the climatic station recorded a precipitation amount of $18.2 \mathrm{~mm}$ (Table 1). This amount of rainfall produced a surface runoff event. Four days later in November 29, a LandSat TM satellite images was acquired (Table 1). The image distinctly demonstrated this event (Figure 3). From the image, the northern and southeastern valleys developed a significant surface runoff in particular W. Al-She'aba, W. Al-Mokhlatt and W.

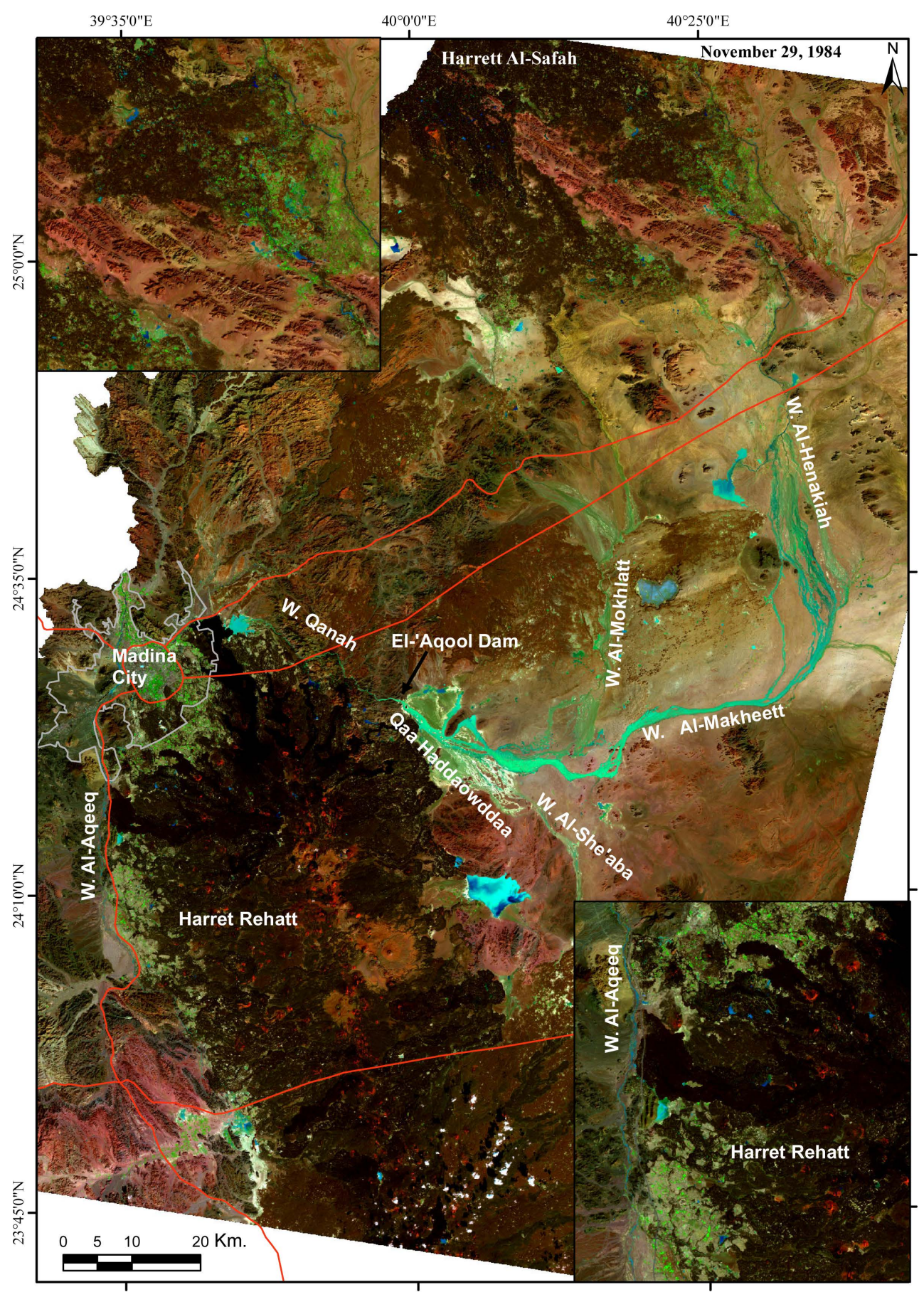

Figure 3. Surface runoff as demonstrated from a LandSat TM image acquired in November 29, 1984. 
Al-Hanakia (Figure 3). In the middle, W. Al-Makhett received surface runoff from the eastern tributaries along with the surface runoff from both W. Al-Mokhlatt and W. Al-Hanakia. However, the spatial extents of surface runoff discloses that the major contribution of surface runoff was from W. Al-Hanakia and W. Al-Makhett (Figure 3). This is probably attributed to the dominance of volcanic rocks in the upstream reaches of W. Al-Hanakia. While the volcanic rocks lack fractures like the acidic igneous rocks, they develop sinks at various spatial extents. Accordingly, water flows on the surface of the volcanic rocks to be collected in these sinks. After filling sinks, water flows through their boundaries into the upstream tributaries of W. Al-Hanakia and W. Al-Makhett (Figure 3). Finally, surface runoff from the three major valleys in the east, north, and southeast of the study had been concentrated in W. Al-Makheett trunk valley that flows in the westward direction into Qa'a Haddaowddaa (Figure 3). At the western end of Qa'a Haddaowddaa, El-'Aqool Dam exists where water of surface runoff overflows in the westward direction through W. Qanah until the north of Madinah city. While surface runoff had been concentrated in the eastern valleys, W. Al-Aqeeq produced potential surface runoff as well. The eastern tributaries originated from Harrat Rehatt to the east of W. Al-Aqeeq were responsible of surface runoff of W. Al-Aqeeq. Developing surface runoff from many major streams that emerge from different directions implies the wide spatial extent of the rainy storm. In addition, although the time intervals between the date of the rainy storm and the acquisition time of the satellite image was nine days, the signature of surface runoff asserted constant and strong flow indicating long precipitation period.

\subsection{The Flash Flood Event of 1987}

In March 3, 1987, the climatic station of Madinah recorded a precipitation amount of $26.8 \mathrm{~mm}$ (Table 1). Figure 4 comprises two images: the first one was acquired in March 4 which is the second day of the rainy storm, and the second one was acquired in March 27 which is 23 days after. The first image of March 4, clearly demonstrated the production of significant surface runoff in the eastern, northern and southeastern valleys (Figure 4). The second image demostrated traces of surface runoff as well along the course of W. Al-Aqeeq and within the sinkhole of the volcanic igneous rocks of Harrett Rehatt (Figure 4). The spectral signatures of surface runoff are strongly represented not only in the major valleys but also in the tributaries of these valleys along with the local

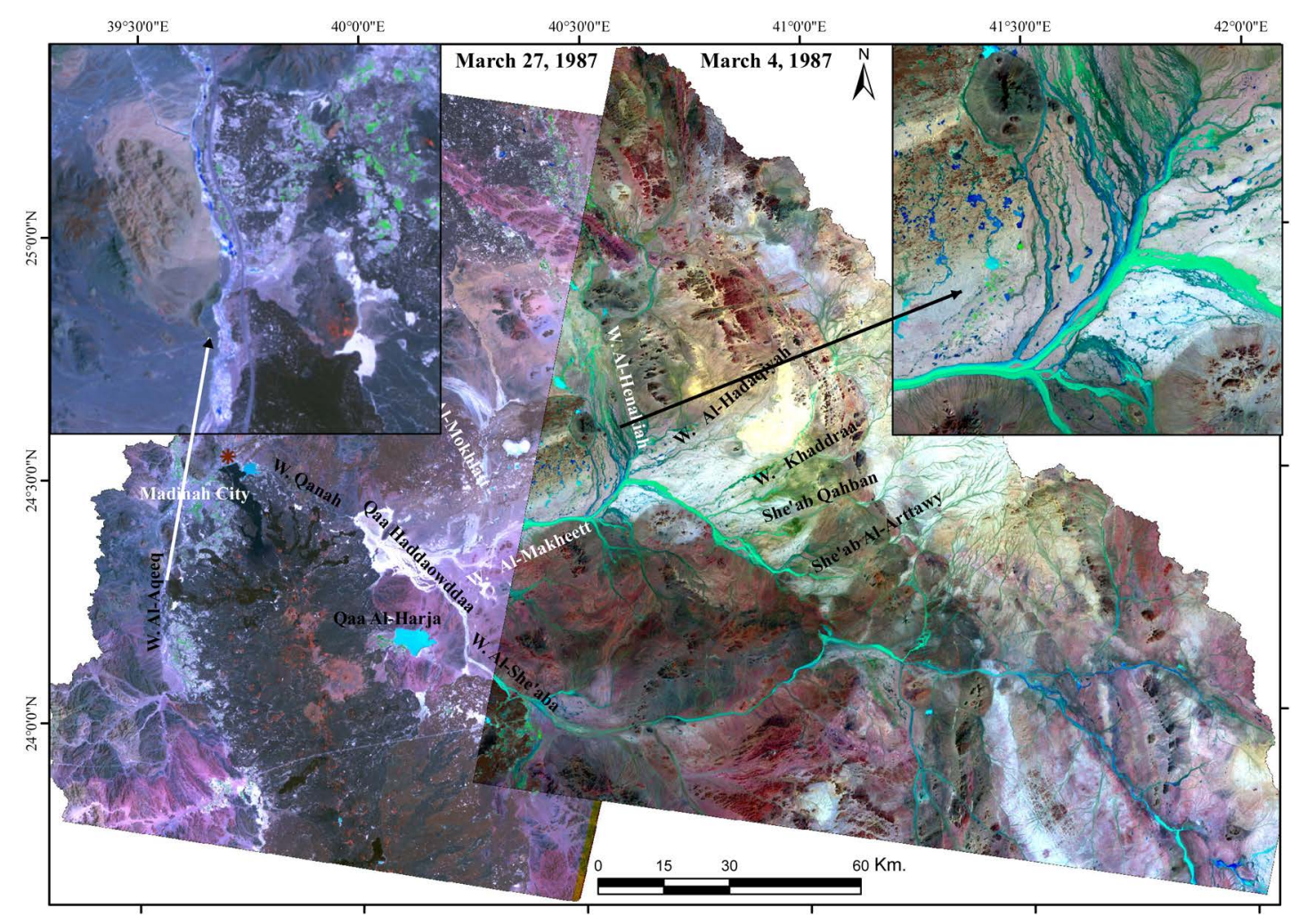

Figure 4. Surface runoff as demonstrated from two LandSat TM images acquired in March 1987. 
small depressions scattered within the floodplains (Figure 4). This pattern of spectral signatures implies that the rainy storm of March 3, 1987 was characterized by wide spatial extents, strong rainfall intensity and long duration of precipitation. It is worthy mentioning that the recorded precipitation associated with this rainy storm (i.e., $26.8 \mathrm{~mm}$ ) represented the total amount of precipitation through March 3, 1987 within a limited aerial extent north of Madianh City in the far west of the study area (Figure 4). Accordingly, the recorded amounts can not express rainfall characteristics that resulted in the extensive surface runoff reflected by the flash flood event of March 1987.

\subsection{Flash Flood Event of 1991}

The amount of precipitation that resulted in developing surface runoff in 1991 was much lower than both of 1984 and 1987 flash flood events which was $6.0 \mathrm{~mm}$ as recorded from Madinah climatic station recorded in January 17, 1991 (Table 1). In the same day, a LandSat TM image was acquired in January 17, 1991. Unlike the previous spatial characteristics of surface runoff associated with surface runoff events in 1984 and 1987, surface runoff was limited to $\mathrm{W}$. Al-She'aba which drains a $7^{\text {th }}$ order drainage basin in the southeast of the study area (Figure 5). Although the spectral signature of surface runoff is well represented in W. Al- She'aba, this runoff had been suddenly ceased at the boundary of Qa'a Haddaowddaa (Figure 5). Analyzing the spatial characteristics of surface runoff may help conclude three implications which are 1) although the recorded amount of precipitation was small, surface runoff had been generated; 2) the rainy storm was concentrated only over the upstream reaches of W. Al-She'aba; and 3) Ceasing surface runoff at the boundary of Qa'a Haddaowddaa refers to low duration of precipitation associated with the rainy storm January 17, 1991.

\subsection{Flash Flood Event of 1998}

In 1998, many rainy storms of various magnitudes occurred through many months. The area of study received various precipitation amounts through five months which are $6.0 \mathrm{~mm}, 10.6 \mathrm{~mm}, 25.0 \mathrm{~mm}, 18.5 \mathrm{~mm}, 10.3 \mathrm{~mm}$, and $38.5 \mathrm{~mm}$ in January $4^{\text {th }}$, March $29^{\text {th }}$, April $29^{\text {th }} \& 30^{\text {th }}$, May $10^{\text {th }}$, and August $28^{\text {th }}$ respectively. In July 1998 , while the climatic station at Madinah City did not register any amount of precipitation, indication of surface runoff have been observed. Luckily, there is a high number of LandSat TM images were acquired through this

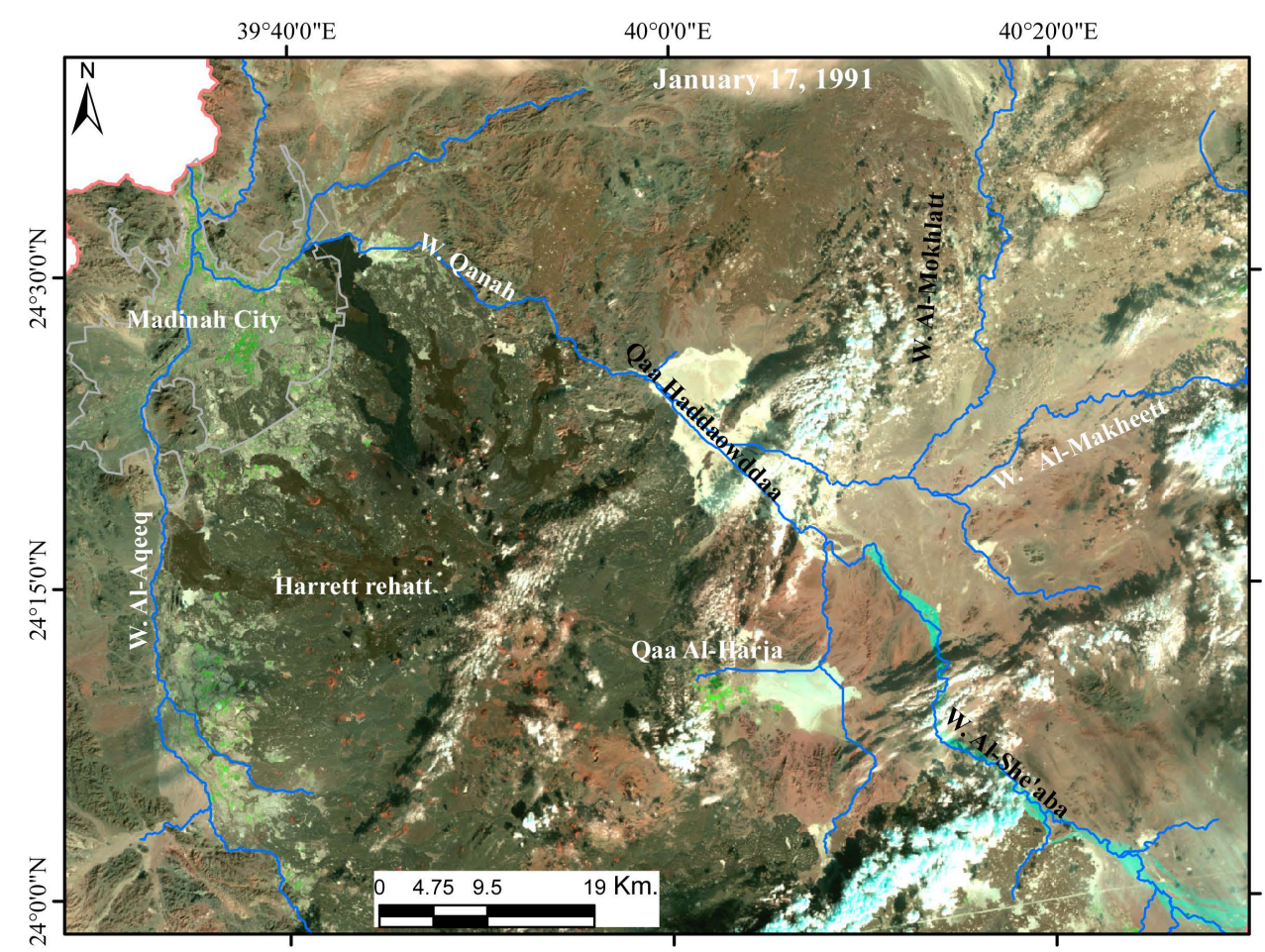

Figure 5. Surface runoff as demonstrated from the LandSat TM image acquired in January 1991. 
year. Accordingly, studying the spectral signatures of surface runoff from this high number of images will help understand the spatial characteristics of surface runoff in the study area. In addition, as TRMM data are monthly available, this will help as well define the spatial distribution of precipitation through each rainy storm and its amount. Unlike all the previous surface runoff events, surface runoff through all the rainy storms is mainly limited to the drainage basin of W. Al-Aqeeq.

In January $4^{\text {th }}, 1998$, Madinah climatic station recorded $6.00 \mathrm{~mm}$ of rainfall while the station did not record any amount of precipitation in February, 1998 (Table 1). The TRMM image of January 1998 shows rainfall data that ranged from 2.9 to $21.8 \mathrm{~mm}$ with an average of $9.3 \mathrm{~mm}$ (Figure 6). The highest values of rainfall occurred in the south and southeast of the study area (Figure 6). However, only W. Al-Aqeeq developed surface runoff. This might be attributed either to the small size of its drainage basin relative to the size of W. Al-She'aba drainage basin which discharges the southeast reaches of the study area, or to a different rainfall intensity in both drainage basins which is higher in the former drainage basin than the later drainage basin. In contrast to the TRMM of January 1998, the TRMM image of February 1998, indicated small amounts of rainfall that ranged from 0.00 to $2.7 \mathrm{~mm}$ with an average of $0.29 \mathrm{~mm}$. The LandSat TM image acquired in March 9, 1998, indicated the presence of traces of surface runoff in W. Al-Aqeeq (Figure 7), and water accumulation southeast Madinah airport. No traces of surface runoff were observed in the eastern, southeastern or northern drainage basins.
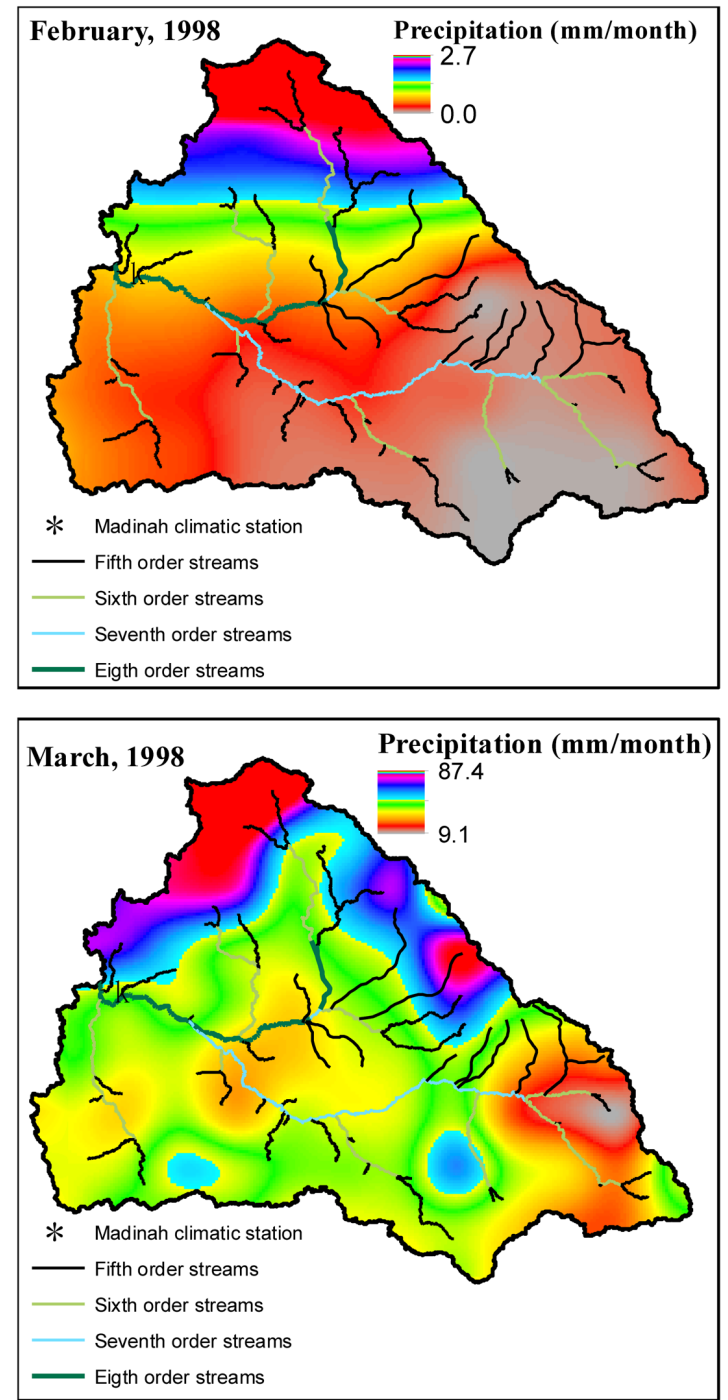
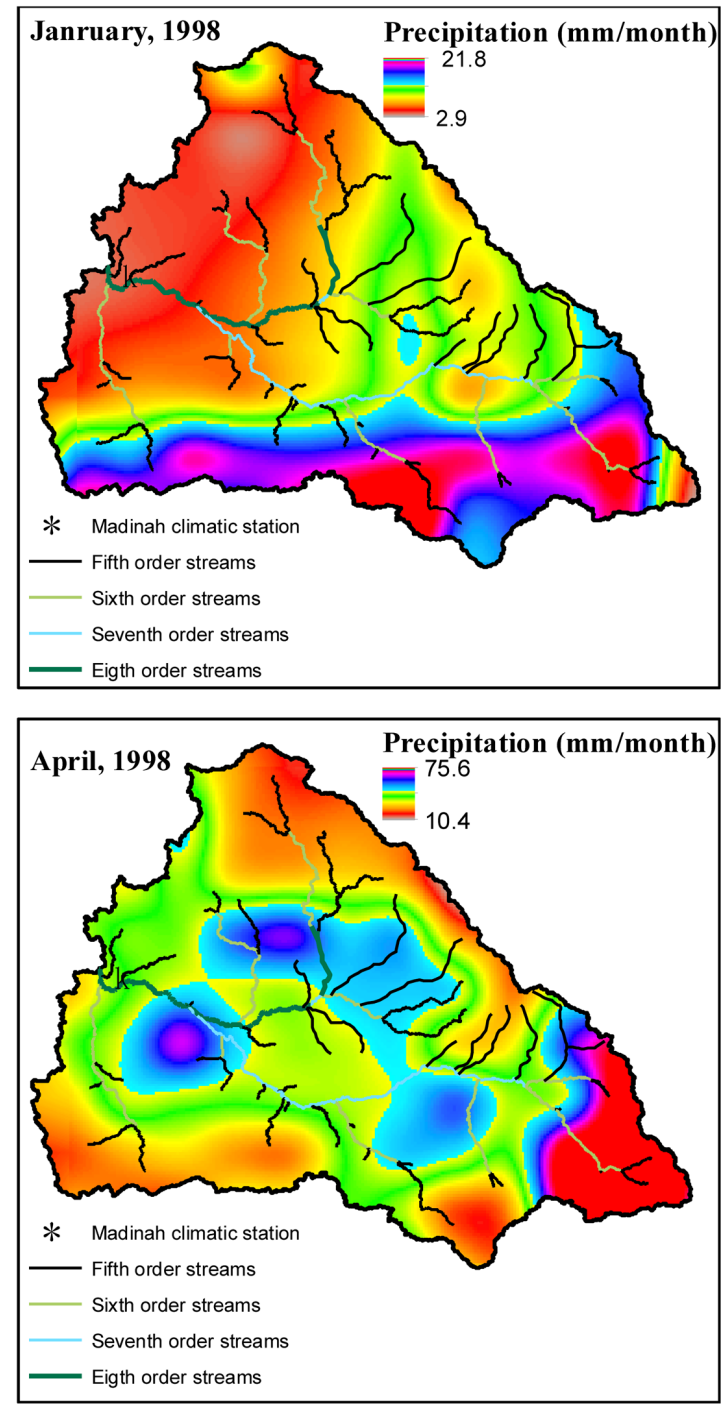

Figure 6. The spatial distributions of monthly rainfall as indicated from TRMM images acquired in January through April 1998. 

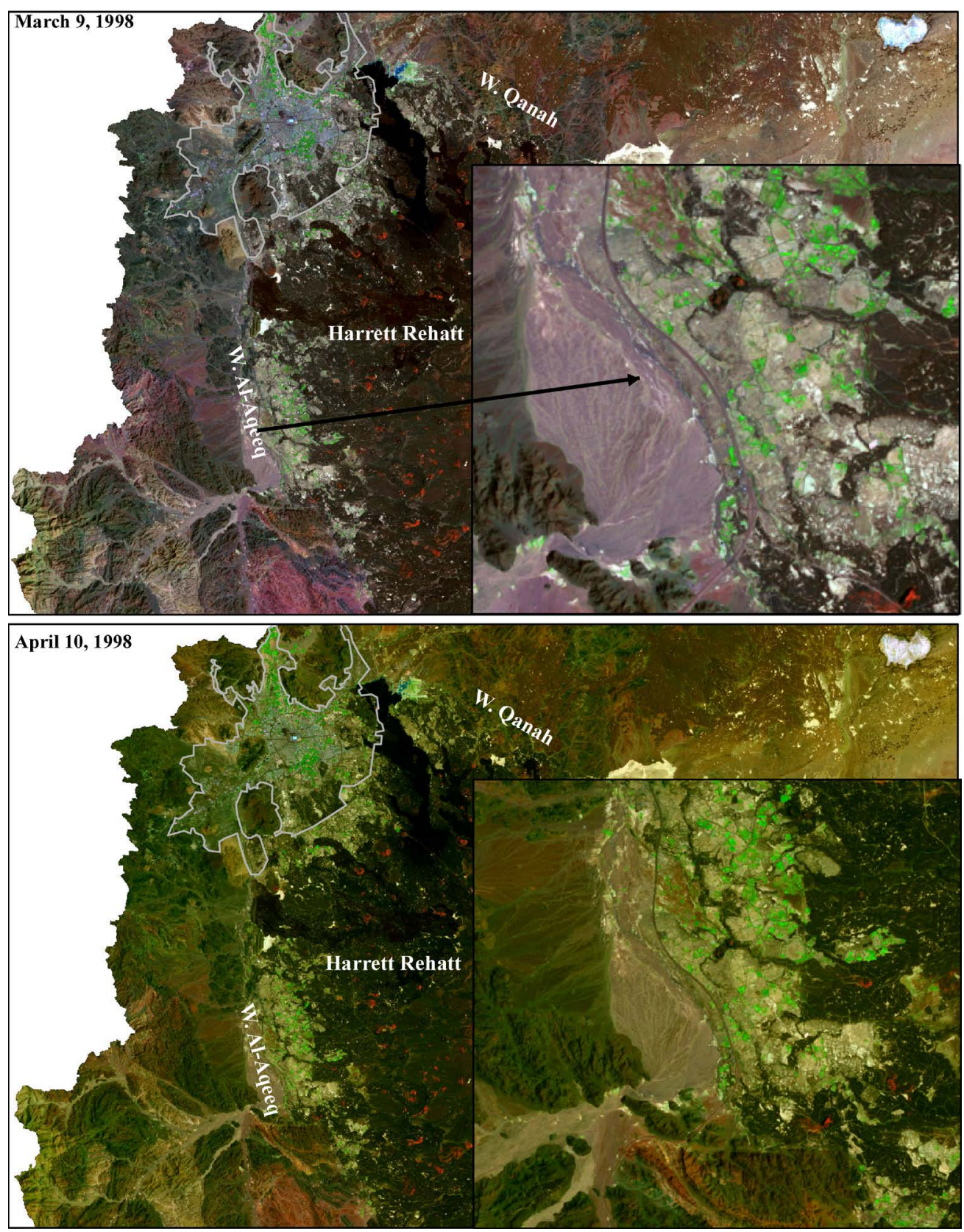

Figure 7. Traces of surface runoff in W. Al-Aqeeq as indicated from LandSat TM images acquired in March 9 (up) and April 10 (down), 1998.

In March 29, 1998, Madinah climatic station recorded an amount of precipitation in the order of $10.6 \mathrm{~mm}$ (Table 1). The TRMM image of March 1998 indicated rainfall amounts ranging from 9.1 to $87.4 \mathrm{~mm}$ with an average of $27.7 \mathrm{~mm}$. The highest amount of precipitation had been observed in the northern and northeast reaches of the study area (Figure 6). Although the precipitation amounts of March that have been recorded by both the climatic station and the TRMM images is higher than those amounts recorded in January 1991, none of the drainage basins in the northern, northeast, and southeast reaches developed surface runoff. This could be attributed either to the large size of these basins or to short duration of precipitation. However, the spectral signatures of surface runoff have been slightly represented along W. Al-Aqeeq drainage basin as indicated from the LandSat TM image acquired in April 10, 1998 (Figure 7).

In April 29 and 30, the study area received precipitation amounts in the order of $25.8 \mathrm{~mm}$ and 18.5 respectively 
as recorded from Madinah climatic station (Table 1). In addition, the station recorded another amount of rainfall in the order of $10.3 \mathrm{~mm}$ in May 10, 1998. These variable amounts had been asserted by the magnitude of rainfall demonstrated in the TRMM images of April 1998 (Figure 6) and May (Figure 8). The precipitation amounts of April TRMM image ranged from 10.4 to $75.6 \mathrm{~mm}$ with an average of $33.3 \mathrm{~mm}$ whereas the precipitation amounts of May TRMM image ranges from 1.1 to $18.8 \mathrm{~mm}$ with an average of $7.7 \mathrm{~mm}$. The highest amounts of precipitation were concentrated over the middle and the southeast of the study area as indicated from the TRMM image of April 1998 (Figure 6). In the TRMM image of May 1998, the highest amounts were widely distributed with more spatial extents over Harrett Rehatt (Figure 8). The rainfall events of both April and May 1998 resulted in surface runoff which is supported by the spectral signatures of the LandSat TM image dated May 28, 1998 (Figure 9). Traces of surface runoff are limited to W. Al-Aqeeq along with water accumulation in Qa'a Haddaowddaa (Figure 9). No traces had been observed in the eastern, northern, and southeastern drainage basins although the TRMM images of both April and May 1998 indicated the presence of high amounts in the upper reaches of these drainage basins (Figures 6-8). This is may be attributed either to the large size of these drainage basins or to the low rainfall intensities over them. Studying the TRMM images of April and May indicated the concentration of the high amounts of precipitation over Harrat Rehatt (Figures 6-8) which may interpret the presence of traces of surface runoff in the trunk valley of W. Al-Aqeeq and water accumulation in Qa'a Haddaowddaa (Figure 9).
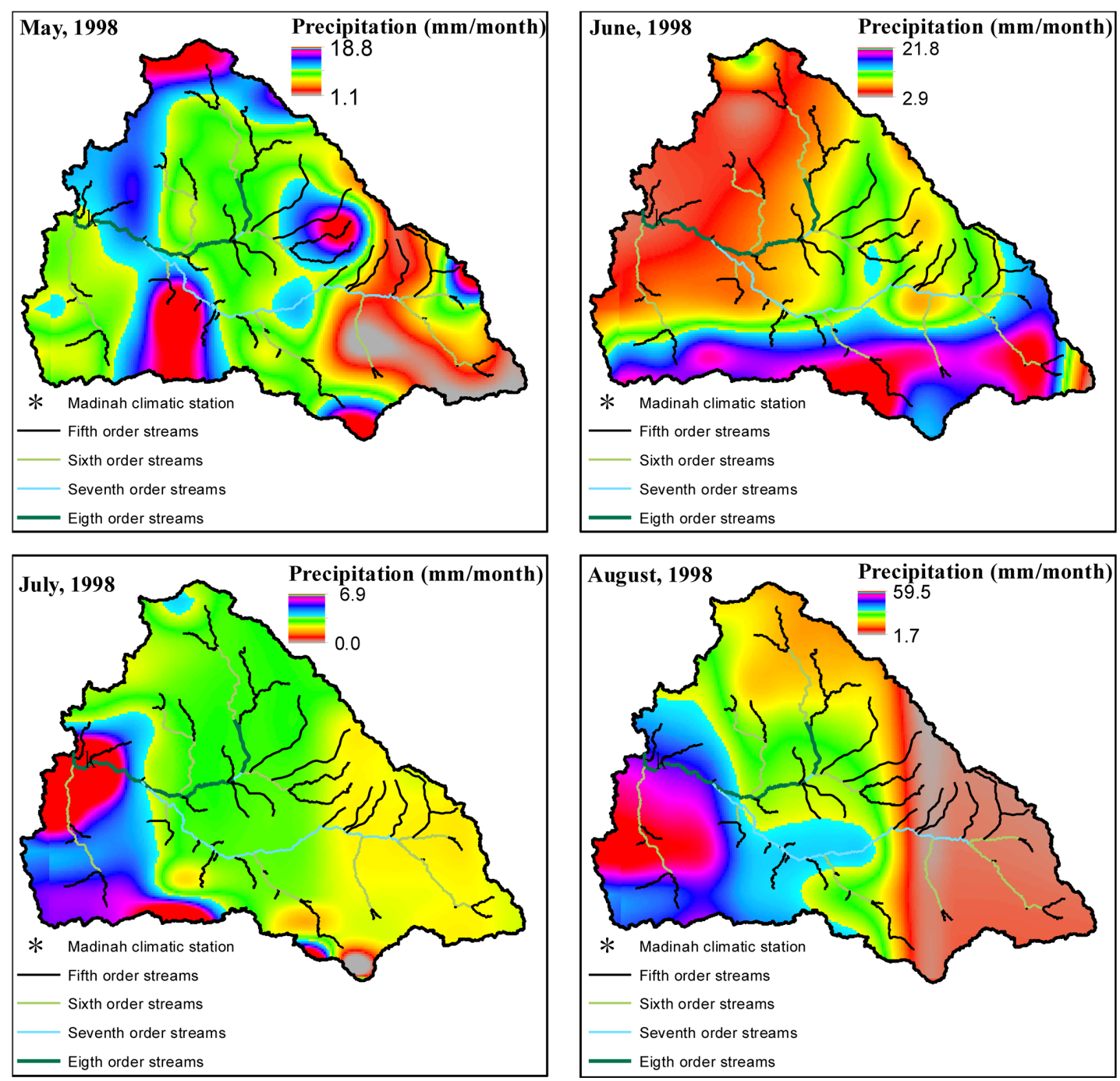

Figure 8. The spatial distributions of monthly rainfall as indicated from TRMM images acquired in May through August 1998. 

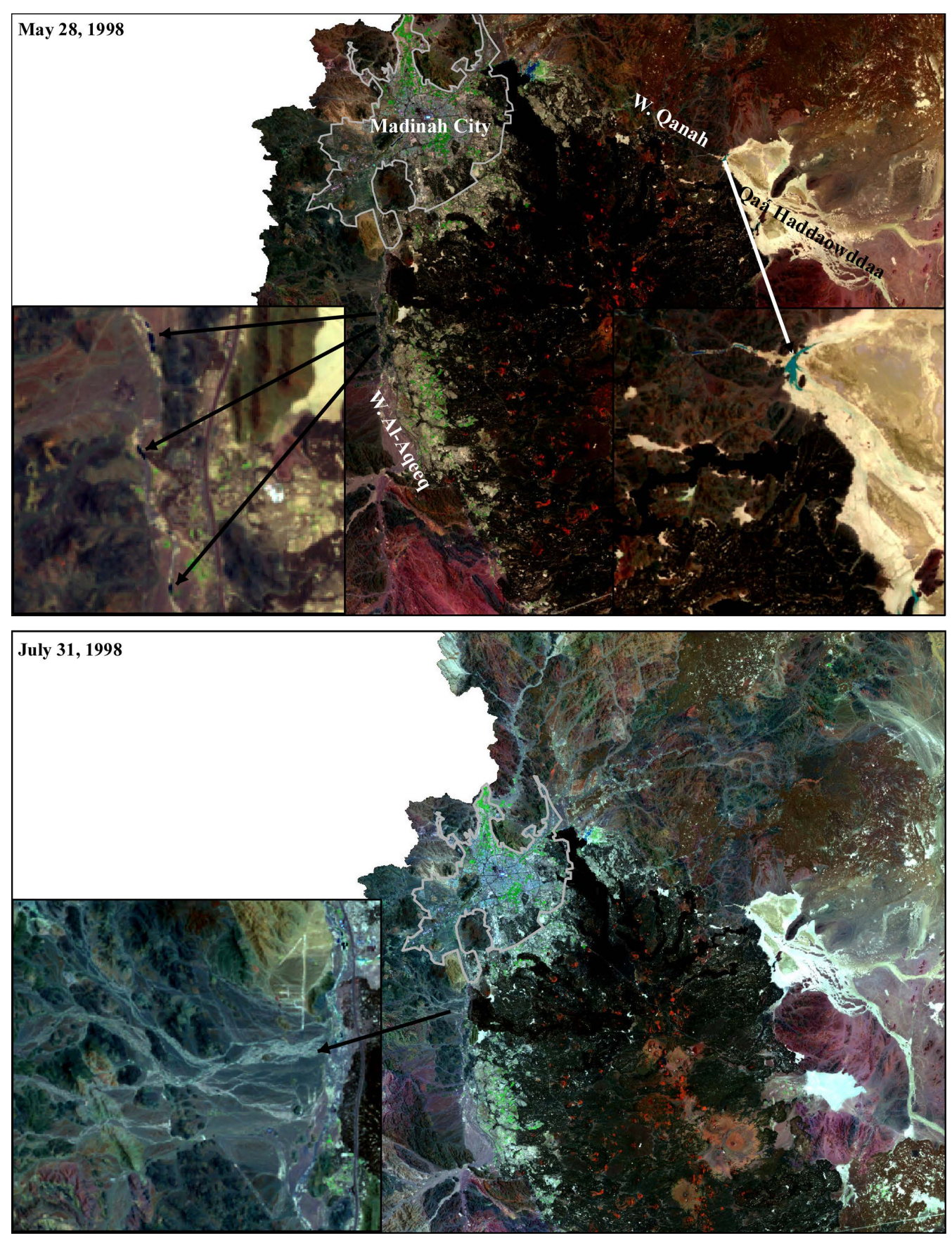

Figure 9. Traces of surface runoff in W. Al-Aqeeq as indicated from LandSat TM images acquired in May 28 (up) and July 31 (down).

Through June and July, no traces of precipitation were recorded by Madinah climatic station. However, traces of surface runoff had been observed in the LandSat TM image acquired at the end of July (Figure 9). Interestingly, this surface runoff was not originated in the upstream reaches of the major valleys in the study area. It had been originated instead from a small drainage basin located directly southwest of Madinah limits (Figure 9). While no precipitation amounts were recorded by Madinah climatic station, the TRMM image of July 1998 clearly indicated that the concentration of the highest rainfall had occurred directly south Madinah city where the surface runoff toke place (Figure 8). This example emphasizes the possibility of using the precipitation data of the TRMM images in monitoring and studying the spatial characteristics of rainfalls and their associated sur- 
face runoffs. This note could be emphasized by studying the major surface runoff event at the end of August 1998.

At the end of August $1998\left(28^{\text {th }}\right)$, an intensive storm had resulted in high amount of precipitation in the order of $38.5 \mathrm{~mm}$ as recorded from Madinah climatic station. The only major valley that developed surface runoff was W. Al-Aqeeq (Figure 10). The spatial distribution and magnitude of the precipitation of the TRMM image of August 1998 asserted this event (Figure 8). The precipitation of the TRMM image ranged from 1.7 to $59.5 \mathrm{~mm}$ with an average of $22.9 \mathrm{~mm}$. The highest amounts of precipitation have been observed over the middle and upstream reaches of $\mathrm{W}$. Al-Aqeeq whereas the lowest amounts of precipitation values occurred over the northern, eastern, and southeastern reaches of the study area (Figure 8). The LandSat TM image acquired in September 1, 1998 demonstrated strong surface runoff in W. Al-Aqeeq trunk valley and its eastern tributaries emerging from Harret Rehatt (Figure 10). On the other hand, no traces of surface runoff are represented in the major valleys of
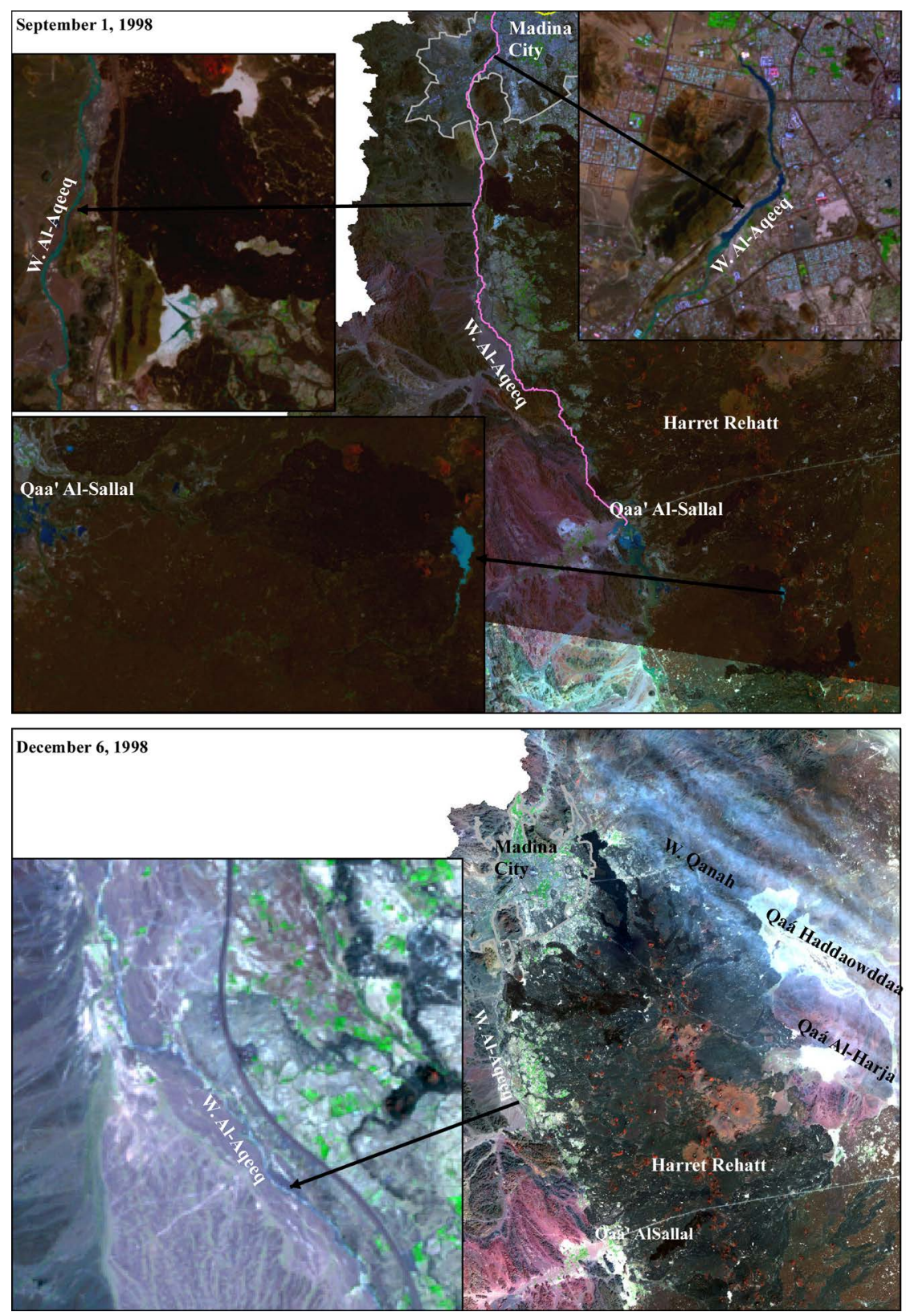

Figure 10. Surface runoff in W. Al-Aqeeq as indicated from the LandSat TM images acquired in September 1, 1998 (up) and December 6, 1998 (down). 
the northern, eastern, and southeastern drainage basins of the study area. The main valley of W. Al-Aqeeq is oriented in the north-south direction with its upstream reaches in the south whereas the downstream reaches is passing through the southern and western limits of Madinah City in the north (Figure 10). It receives surface runoff from both eastern and western tributaries. The western tributaries discharge a terrain comprising acidic igneous complexes, whereas the eastern tributaries discharge the volcanic rocks of Harrat Rehatt. The LandSat TM images indicated that the highest contribution of surface runoff in W. Al-Aqeeq occurred from the eastern terrains where volcanic rocks are located (Figure 10).

At the end of 1998 through October and November, no traces of precipitation were recorded by Madinah climatic station. Nevertheless, traces of slight surface runoff could be recognized from the Landsat TM image acquired in December 6, 1998 (Figure 10). The TRMM precipitation images of October 1998 support this notewhere the area of study generally receives limited amount of precipitation ranging from 0.0 to $2.0 \mathrm{~mm}$ with an average of $0.5 \mathrm{~mm}$ (Figure 11). The precipitation amounts of November ranged from 0.0 to $12.00 \mathrm{~mm}$ with an average of $1.3 \mathrm{~mm}$ (Figure 11). However, the highest amounts of precipitation in both images had been concentrated in the southwestern reaches of the study area which might be responsible for the slight surface runoff in W. Al-Aqeeq (Figure 10).

From the above discussion, important considerations could be outlined which include:

- Although the valleys of W. Al-Hanakia, W. Al-Mohkhlatt, W. Al-Makheett, and W. Al-She'aba developed surface runoffs from the northern, eastern and southeastern reaches of the study area respectively through the flash flood of 19984, 1987, and 1991, the valley of W. Al-Aqeeq is considered the most frequently flowing valley as it developed surface runoff through the majority of precipitation events. This notion may be attributed to the dominance of volcanic rocks on the eastern side of $\mathrm{W}$. Al-Aqeeq. The volcanic rocks are capable to collect water in the volcanic sinkholes which eventually produce surface runoff in the upstream tributaries of W. Al-Aqeeq valleys,

- According to the available records of precipitation from Madina City climatic station along with the monthly TRMM images, there is no specific threshold of precipitation amounts that produce surface runoff. For instance, in response to a $6.0 \mathrm{~mm}$ precipitation amounts, surface runoff is varied from no surface runoff in the northern and eastern drainage basins (e.g., W. Al-Hanakia, W. Al-Mokhlatt, and W. Al-Makhett), limited surface runoff in the southeastern drainage basins (W. Al-She'eba), to full surface runoff in Al-Aqeeq drainage basin. Although the northern, eastern, and southeastern drainage basins developed significant surface runoff in 1984 and 1987 in response to precipitation amounts in the order of 18.2 and 26.8, the 1998 TRMM images of January, March, April, May, and June indicated the occurrence of similar and higher amounts of precipitation, however, no surface runoff had been developed in these drainage basins. This is may be attributed to the short duration precipitation events and/or low rainfall intensity along with the size of the drainage basins and lithology of these drainage basins, and
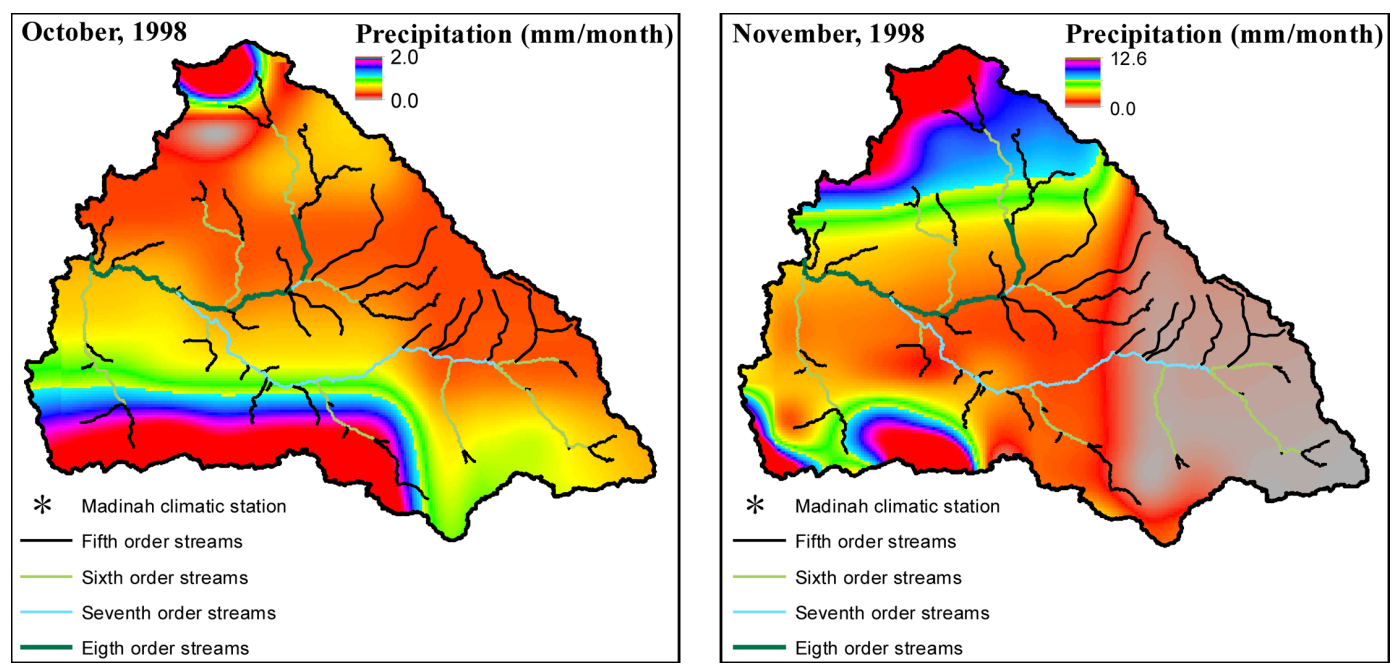

Figure 11. The spatial distributions of monthly rainfall of both October and November 1998 as indicated from TRMM images. 
- Although Madinah climatic station provided a good indication on the occurrence of surface runoff, however, its record still represents a point data that could not provide the spatial distribution and magnitude of precipitation over the entire study area. In addition, the upstream reaches may develop a surface runoff in response to a local rainy storm while the climatic station does not provide any record of precipitation. In contrast, and although they are not calibrated, the TRMM images can potentially provide better representation of the spatial distribution and magnitude of the rainy storms that results in surface runoff.

\section{Conclusion}

The major valleys in the study area are highly qualified to develop surface runoff that produce potential surface runoff events. The spatial characteristics and magnitudes of these events still require more detailed study. The multi-temporal optical satellite imagery along with the TRMM images can potentially help in the understanding of many aspects of the spatial characteristics of the flash floods events in the study area. Not all the valleys produce surface runoff in a single rainy storm. Although Madinah climatic station can provide good record of precipitation, however, its precipitation records represent a limited geographic area and could not express the spatial variability and the magnitude of precipitation over the entire area of study. Although not calibrated, the TRMM images can help determine the spatial variabilities of the magnitude of precipitation over the entire study area. However, to determine the magnitude of surface runoff along with the various hydrological parameters of the study area, more requirements should be allocated such as extra multi-temporal satellite imagery, fine resolution Digital Elevation Model, and appropriate networks of gauge and climatic stations over the study area. Given this, sophisticated models of surface runoff can be developed to accurately assess the spatial characteristics and magnitude of surface runoff for eventual maximizing harvesting water from surface runoff, and minimizing the potential hazards of the associated flash floods.

\section{References}

[1] Subyani, A. and Bayumi, T. (2001) Physiographical and Hydrological Analysis of Yalamlam Basin, Makkah AlMukarramah Area. JKAU: Earth Sciences, 13, 151-177.

[2] El-Barodi, M. and Mirza, M. (2005) Morphologic and Hydrologic Characteristics of the Fluvial Valleys within Al-Haram Region. Journal of Umm Al-Qura University for Educational and Social Sciences, 17, 385-433. (In Arabia)

[3] Bourouba, M. (2007) Hydro-Morphometric Studies for Flash Flood Estimation in Wadi Autod Drainage Basin, Saudi Arabia. Gulf and Arab Peninsula Studies Center, Special Issue Periodicals, 21, 1-145. (In Arabic)

[4] Fred, E. and Mostafa, B. (2008) Flood Risk Modeling for Holy Sites in Makkah. Proceedings of the Symposium on National GIS Applications, Al-Kober City, 1-12.

[5] Al-Juaidi, F. (2008) Hydro-Morphometric and Flash Flood Characteristics of the Drainage Basins Proposed for Dam Installations on the Valleys of Aliya Drainage Basin, Al-Kharj Governorate. Geographical Research Journal, 84, 1-57. (In Arabic)

[6] Dawood, G., Mirza, M. and Al-Ghamdi, K. (2012) GIS-Based Estimation of Flood Hazard Impacts on Road Network in Makkah City, Saudi Arabia. Environmental Earth Science, 67, 2205-2215. http://dx.doi.org/10.1007/s12665-012-1660-9

[7] Al-Juaidi, F. and Borobah, M. (2007) Estimation of Peak Hydrograph of Floods in Wadi Al-Ain Catchment. Geographic Research Center, King Saud University, 40. (In Arabic)

[8] El-Barodi, M. (2012) Flash Flood Estimation and Hazards of WadiUranah Southeast Makkah Using GIS. Geographical Research Series, Egyptian Geographic Society. (In Arabic)

[9] Al-Juaidi, F. (2005) Using Fine Spatial Resolution Remote Sensing Imagery for the determination of Flash Flood Extents in Al-Kharj Plain. Saudi Geographical Society, 71. (In Arabic)

[10] Al-Ghamdi, S. (2006) Using GIS for Extracting Morphometric Parameters from Digital Elevation Models: A Case Study of Wadi Zora, Saudi Arabia. Kuwait Geographical Society, 317. (In Arabic)

[11] Al-Hawwas, A.A. (2007) Integration of Remote Sensing and GIS Techniques for the Determination and Analysis of Hydro-Morphometric Characteristics of Desert Drainage Basins. Saudi Geographical Society, Geographical Research, 18. (In Arabic)

[12] El-Bastawesy, M.A., Ali, R.R. and Nasr, A.H. (2008) The Use of Remote Sensing and GIS for Catchment Delineation in Northwestern Coast of Egypt: An Assessment of Water Resources and Soil Potential. The Egyptian Journal of Remote Sensing and Space Sciences, 11, 3-16. 
[13] El-Bastawesy, M., White, K. and Nasr, A.H. (2009) Integration of Remote Sensing and GIS for Modeling Flash Flood in Wadi Hudain Catchment, Egypt. Hydrological Processes, 13, 1359-1368. http://dx.doi.org/10.1002/hyp.7259

[14] Abou El-Magd, I.H., Hermas, E.A. and El-Bastawesy, M.A. (2010) Integration of Hydrological Modeling and GIS for Assessment and Prediction of Natural Hazards in Abu Dabbab Area, Red Sea Region, Egypt. The Egyptian Journal of Remote Sensing and Space Sciences, 13, 81-88. http://dx.doi.org/10.1016/j.ejrs.2010.07.010

[15] Dawood, G. and Koshak, N. (2011) Developing GIS-Based Unit Hydrograph for Flood Management in Makka Metropolitan Area, Saudi Arabia. Journal of Geographic Information System, 3, 153-159. http://dx.doi.org/10.4236/jgis.2011.32012

[16] Dawood, G., Mirza, M. and Al-Ghamdi, K.A. (2011) Assessment of Several Flood Estimation Methodologies in Makkah Metropolitan Area, Saudi Arabia. Journal of Geographic Information Systems, 3, 217-233.

[17] Koshak, N. and Dawood, G. (2011) A GIS Morphometric Analysis of Hydrological Catchments within Makkah Metropolitan Area, Saudi Arabia. International Journal of Geomatics and Geosciences, 2, 544-554.

[18] Al-Ghamdi, K., Mirza, M. and El Zahrany, R. (2011) GIS Evaluation of Urban Growth and Flood Hazards: A Case Study of Makkah City, Saudi Arabia. TS07D-GIS Applications, 5479, FIG Working Week, Knowing to Manage the Territory, Protect Environment, Evaluate the Cultural Heritage, Rome, 6-10 May 2011, 24 p.

[19] Al-Shantti, A.M. (1993) Geology of Arabian Shield. Center of Scientific Research, King Abdul Aziz University, Jeddah.

[20] Mirza, M. (2008) Structural and Morphological Characteristics of Harrats (Volcanic Eruptions) West of Saudi Arabia with Emphasis on Central Harrats: Harrat Kishb as a Case Study. Journal of Faculty of Social Sciences, 20, 197-382.

[21] Al-Shareef, A.S. (1998) Geology of Madina (Environment and Human). Madinah Al-Munwarrah Art Club, Madinah Al-Munwarrah.

[22] Scholz, A. (1972) The Construction of Morphographic and Morphometric Maps. In: Demek, J., Ed., Manual of Detailed Geomorphological Mapping, Academia, Publishing House of the Czechoslovak Academy of Sciences, Prague.

[23] Jensen, S.K. and Domingue, J.O. (1998) Extracting Topographic Structure from Digital Elevation Data for Geographic Information System Analysis. Photogrammetric Engineering and Remote Sensing, 54, 1593-1600. 